\title{
Audit of the Effect of Non-Nasal Specific Scoring On the Postoperative Snot22 Questionnaire
}

\author{
Samir Gendy \\ Emersons Green/Devizes NHS Treatment Centres
}

Corresponding Author: Samir Gendy, Emersons Green/Devizes NHS Treatment Centres

Received Date: August 11, 2020; Accepted Date: August 30, 2020; Published Date: September $28,2020$.

Citation: Gendy S., (2020) Thyroidectomy under Local Anaesthesia; Experience from a Tertiary Hospital in Kumasi, Ghana. Journal of Clinical Otorhinolaryngology, 2(2); Doi: 10.31579/2692-9562/010

Copyright: ( 2020 Samir Gendy, This is an open-access article distributed under the terms of the Creative Commons Attribution License, which permits unrestricted use, distribution, and reproduction in any medium, provided the original author and source are credited.

\section{Abstract}

The Sino-nasal outcome test (SNOT22) has been widely adopted in clinical practice and has been declared as the most suitable sinonasal outcome scoring system. It is simple disease specific encompassing 22 symptoms reflecting health burden of the rhino- logical patients.

Each item quantifies symptoms severity from 0(no problem) to 5 (worst symptom). The sum of each item results in a maximum score of 110 . High score indicates poor outcome.

Keyword: Sino-nasal outcome test; sinonasal

\section{Introduction}

The Sino-nasal outcome test (SNOT22) has been widely adopted in clinical practice and has been declared as the most suitable sinonasal outcome scoring system. It is simple disease specific encompassing 22 symptoms reflecting health burden of the rhino- logical patients.

Each item quantifies symptoms severity from 0 (no problem) to 5 (worst symptom). The sum of each item results in a maximum score of 110 .High score indicates poor outcome.

SNOT22 is recommended by the European Position Paper on Rhinosinsuitis and Nasal polyps EPOS 2012 as the most adequate tool to evaluate the effectiveness of surgery for chronic rhino sinusitis.(1)

The SNOT22 Questionnaire includes 9 non nasal specific symptoms that affects the preoperative and postoperative scoring of various rhinological surgical procedures.

The 9 non nasal specific symptoms are divided into 2 main categories:

A- Quality of life related (difficult falling asleep, wake up at night, wake up tired, and fatigue, reduced productivity, reduced concentration).

B- Psychologically related (frustrated/restless, sad, embarassed)

The Aim of this Audit is to study the effect of these 9 non nasal symptoms on various Rhinological Surgical procedures performed by a single Surgeon at Both Emersoons Green/Devizes NHS Treatment Centres in the period from May 2019 till December 2019.

\section{Materials and Methods}

A Total of 20 patients were randomly selected who hard various nasal surgeries performed by named ENT surgeon at Emersons Green/Devizes NHS treatment Centres in the period from May 2019-Decemeber 2019.

Every patient was seen preoperatively in the outpatient clinic where he/she scored his /her symptoms using the SNOT 22 questionnaire chart, 6 weeks postoperatively he/she scored again her symptoms using SNOT22 questionnaire unaware of their preoperative SNOTT -22 scores and a special focus was put on patient's scoring of non-nasal specific symptoms

The Cohort Age varied from the youngest of 19 years old to the oldest of 59 years old, Various Rhinological Procedures was performed including: Septoplasty , Functional Endoscopic sinus surgery(FESS) with or without Polypectomy, and Endoscopic Turbinoplasty.

All patients had a preoperative Counselling and received an information leaflet about their nasal procedure in addition to SNOT22 Questionnaire chart. Routine blood investigations, informed Consent was signed in the clinic. 


\section{Sino-Nasal Outcome Test-22 Questionnaire v4}

Below you will find a list of symptoms and sodialemotiona consequences of your nasal dscrder. We woud like to know more about these proclems and would appreclate you answering the following question to the best of your ability. There are no right or wrong answers, and only you can provide us with this intomation. Please rate your problems, as they have been over the past two weeks. Thank you for your participaton.

\begin{tabular}{|c|c|c|c|c|c|c|}
\hline 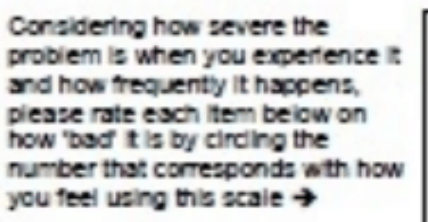 & $\begin{array}{l}\text { No } \\
\text { problem }\end{array}$ & $\begin{array}{l}\text { Very mild } \\
\text { probiem }\end{array}$ & $\begin{array}{l}\text { Mild or } \\
\text { elloht } \\
\text { problem }\end{array}$ & $\begin{array}{l}\text { Moderate } \\
\text { problem }\end{array}$ & $\begin{array}{l}\text { Sovere } \\
\text { problem }\end{array}$ & $\begin{array}{l}\text { Problem } \\
\text { ac bed se } \\
\text { it oan be }\end{array}$ \\
\hline 1. Need to blow nose & 0 & 1 & 2 & 3 & 4 & 5 \\
\hline 2. Sneezing & D & 1 & 2 & 3 & 4 & 5 \\
\hline 3. Runny nose & $\overline{0}$ & 1 & 2 & 3 & 4 & 5 \\
\hline 4. Cough & D & 1 & 2 & 3 & 4 & 5 \\
\hline 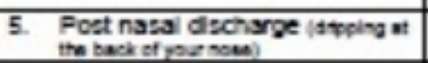 & D & $\overline{1}$ & 2 & 3 & 4 & 5 \\
\hline 6. Ther nass decharge & D & 1 & 2 & 3 & 4 & 5 \\
\hline 7. Ear fuline:s: & 0 & 1 & 2 & 3 & 4 & 5 \\
\hline B. Daziness & 0 & 1 & 2 & 3 & 4 & 5 \\
\hline 9. Earpain/preasure & 0 & 1 & 2 & 3 & 4 & 5 \\
\hline 10. Facis painjpressure & 0 & 1 & 2 & 3 & 4 & 5 \\
\hline 11. Dificulty fa ing azieep & 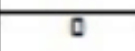 & 1 & 2 & 3 & 4 & 5 \\
\hline 12. Waking up x: night & D & 1 & 2 & 3 & 4 & 5 \\
\hline 13. LSck of a good niprts setep & O & 1 & 2 & 3 & 4 & 5 \\
\hline 14. Waking up tred & D & 1 & $\overline{2}$ & 3 & 4 & 5 \\
\hline 15. Fasgue during the day & 0 & 1 & 2 & 3 & 4 & 5 \\
\hline 16. Reduced productivity & D & 1 & 2 & 3 & 4 & 5 \\
\hline 17. Reduced concentration & D & 1 & 2 & 3 & 4 & 5 \\
\hline 18. Fruatratedreatese/mabie & 0 & 1 & 2 & 3 & 4 & 5 \\
\hline 19. Sad & 0 & 1 & 2 & 3 & 4 & 5 \\
\hline 20. Embarazotd & D & 1 & 2 & 3 & 4 & 5 \\
\hline 21. Sense of tastesmel & 0 & 1 & 2 & 3 & 4 & 5 \\
\hline 22. Elockagelcongetion of note & O & 1 & 2 & 3 & 4 & 5 \\
\hline
\end{tabular}

TOTAL:

Postoperatively all patients received oxymetazoline nasal drops $0.05 \% 2$ drops twice daily for 5 days followed by isotonic Sterimar nasal sprays for 2 weeks, A 10 days course of $500 \mathrm{mg}$ Clarithromycin antibiotic 12 hourly was prescribed in selected FESS Polypectomy patients where signs of active infection was illustrated intra-operatively.

All patients were seen 6 weeks postoperatively to assess their symptoms clinically and by SNOT22 questionnaire chart with a focus on the score of non-nasal specific symptoms

The Pre-operative SNOT22 score off all 20 patients ranged was from 92 and 15 with a mean score of 43 and the post-operative SNOT22 score ranged from 15 and 0 with a mean of 6 with an overall of $71 \%$ improvement in patient's symptoms as illustrated in Figure 1.
A total of 7 patients (30\%) scored postoperatively a single or multiple non nasal specific symptom that affected the total outcome score of SNOT22 questionnaire, 4 patients had septoplasty procedures 2 patients had Endoscopic Turbinoplasty Procedures while only 1 patient had a Unilateral FESS procedure.

6 patients scored 1 in one or more of the non-nasal specific symptoms while one patient who had unilateral FESS scored 4 in 3 symptoms of lack of good night's sleep, wake up tired, and wake up at night and score of 1 at symptoms of reduced productivity and concentration in addition of being restless and irritable with overall postoperative SNOT22 score of 31 compared to 85 preoperatively.

The Demographics of these 7 patients is illustrated in Figure 2 


\begin{tabular}{|c|c|c|c|}
\hline PROCEDURE & $\begin{array}{l}\text { Preop.SNOT22 } \\
\text { SCORE }\end{array}$ & $\begin{array}{l}\text { Postop.SNOT22 } \\
\text { Score }\end{array}$ & Postop. Non-nasal specific score \\
\hline FESSPOL YPECTOMY & 31 & 1 & $\overline{0}$ \\
\hline FESSPOL YPECTOMY & 40 & 1 & 0 \\
\hline RT FESS POL YPECTOMY & 42 & 0 & 0 \\
\hline Revision Fess Polypectomy & 32 & 0 & 0 \\
\hline FESS Polypectomy & 61 & 0 & 0 \\
\hline Turbinoplasty & 20 & 6 & 0 \\
\hline FESS & 25 & 0 & 0 \\
\hline Turbinoplasty & 43 & 8 & 5 \\
\hline Septoplasty & 48 & 3 & 1 \\
\hline FESS Polypectomy & 18 & 5 & 0 \\
\hline FESS & 85 & 31 & 18 \\
\hline FESS Polypectomy & 47 & 6 & 0 \\
\hline Septoplasty & 92 & 13 & 6 \\
\hline FESS Polypectomy & 52 & 2 & 0 \\
\hline Turbinoplasty & 15 & 2 & 0 \\
\hline Revision FESS & 29 & 0 & 0 \\
\hline Septoplasty & 60 & 13 & 4 \\
\hline
\end{tabular}

Figure 1. Summary of preop. \& postop. Scores of various nasal surgeries

$\begin{array}{ll}\text { Total no. of patients } & \text { Postop.Symptom } \\ 6 & \text { wake up tired } \\ 3 & \text { reduced productivity } \\ 1 & \text { frustrated } \\ 3 & \text { reduced concentration } \\ 2 & \text { Fatigue during day } \\ 1 & \text { sad } \\ 1 & \text { embarassed }\end{array}$

Figure 2. Illustrating postoperative non-nasal specific symptoms 


\section{Discussion}

The 22-item Sino-Nasal-Outcome test (SNOT22) is a widely applied patient-reported outcome instrument used to assess the severity of symptoms associated with chronic Rhinosinusitis.

However recent publication suggest that it is also a validated outcome that can measure the improvement of patient's symptoms post Nasal Obstruction and sinus Surgical procedures , as septoplasty, turbinoplasty (2) , and endoscopic sinsus surgery(3)

Kennedy etal. Grouped the SNOT 22 questions into 4 main categories:

Nasal related (need to blow nose, sneezing, runny nose, nasal obstruction, loss of smell/taste and post nasal drip.)

Ear/Facial related (ear fullness, dizziness, ear pain, facial pain\&pressure)

Quality of life related (difficult falling asleep, wake up at night, wake up tired, and fatigue, reduced productivity, reduced concentration)

Psychologically related (frustrated/restless, sad, embarrassed), Kennedy etal. Concluded that SNOT-22 is helpful tool for quantifying changes in symptoms and can be used to predict extent of post-operative improvement. While all of the components of the SNOT-22 significantly improved after surgery, only runny nose, as well as cough were independent predictors of post-surgical SNOT22improvement.(4)

This study revealed that non-nasal specific symptoms affected $30 \%$ of patients (7patients) hence SNOT22 postoperative scores which is reflected on the outcome of various nasal surgeries waking up tired was the commonest symptom( 6 patients) that was recorded 6 weeks postoperatively but can't be directly correlated with surgical procedures.

\section{Conclusion}

SNOT22 Questionnaire is a validated assessment of various nasal surgical procedures.

This study although of a small cohort of patients(20) revealed that $70 \%$ improvement of SNOT22 scores postoperatively but also highlighted that 7 patients $(30 \%)$ recorded various scores of non -nasal specific symptoms that had an implication on the postoperative outcome scores.

\section{References}

1. Snidvongs K, Heller GZ, Harvey RJ. (2014). Validity of European Position Paper on Rhino sinusitis disease control assessment and modification in Chronic Rhino sinusitis.Otolaryng. Head Neck Surg. 150(3):479-86.

2. H.H.Kordjian. (2017). Sixty-Three patient-based survey-Can SNOT-22test be a suitable evaluation method for septoplasty and turbinectomy Clin.Otolaryng. 42 (6):1373-137

3. ZacharyM, RabunJones, Phong le, etal. (2018). SNOT-22 outcomes after sinus surgery a systematic review and metaanalysis. Laryngoscope, 128(3):581-592

4. Kennedy J., Hubbard.M.,Huyett.P, etal. (2013). SNOT-22: A predictor of post-surgical improvement in patients with chronic sinusitis. Ann Allergy Asthma Immunol. ;111(4):246-251
This work is licensed under Creative Commons Attribution 4.0 License

To Submit Your Article Click Here: Submit Article

DOI: $10.31579 / 2692-9562 / 010$

\footnotetext{
Ready to submit your research? Choose Auctores and benefit from:

* fast, convenient online submission

* rigorous peer review by experienced research in your field

* rapid publication on acceptance

* authors retain copyrights

* unique DOI for all articles

* immediate, unrestricted online access
}

At Auctores, research is always in progress.

Learn more www.auctoresonline.org/journals/journal-of-clinicalotorhinolaryngology- 